\title{
CORRECTION
}

\section{Correction to: Characterization of radioactive cobalt on graphene oxide by macroscopic and spectroscopic techniques}

\author{
Zhongxiu Jin $^{1} \cdot$ Jie Sheng ${ }^{1} \cdot$ Yubing Sun ${ }^{2}$
}

Published online: 7 May 2019

(c) Akadémiai Kiadó, Budapest, Hungary 2019

\section{Correction to: J Radioanal Nucl Chem (2014) 299:1979-1986 https://doi.org/10.1007/s10967-013-2918-8}

Figure 1a has been published incorrectly in the original article in which there is a mistake in characterization of graphene oxide (XRD pattern) due to the odd repetition of background. The correct version of Fig. 1a is provided in this correction.

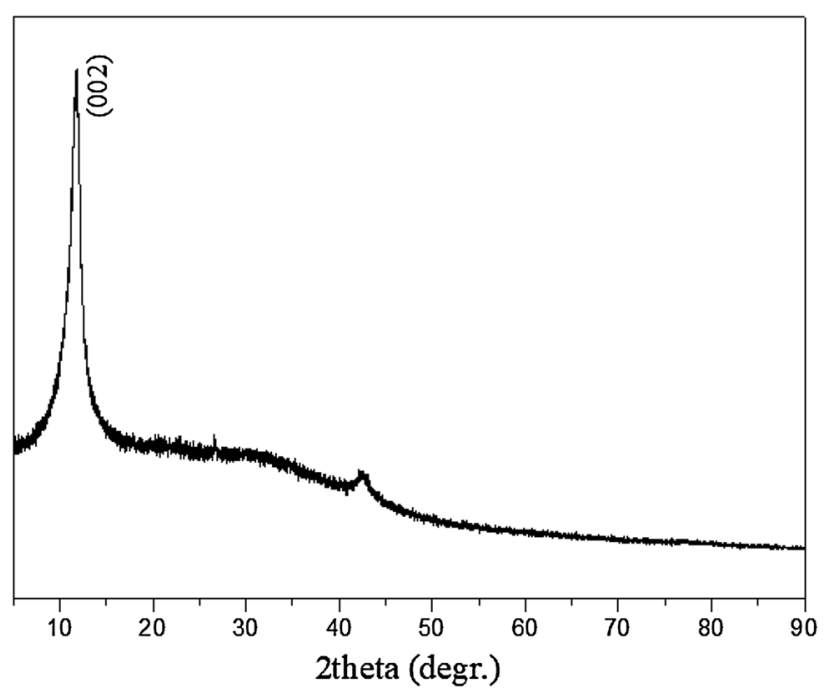

Fig. 1 The characterization of GO. a XRD pattern

Publisher's Note Springer Nature remains neutral with regard to jurisdictional claims in published maps and institutional affiliations.

The original article can be found online at https://doi.org/10.1007/ s10967-013-2918-8.

Yubing Sun

sunyubing@126.com

1 The School of Public Health, Anhui Medical University, Hefei 230032, People's Republic of China

2 Key Laboratory of Novel Thin Film Solar Cells, Institute of Plasma Physics, Chinese Academy of Science, P.O. Box 1126, Hefei 230031, People's Republic of China 